\title{
The Crystal Structure of HfAl
}

\author{
LARS-ERIK EDSHAMMAR
}

Institute of Inorganic and Physical Chemistry, University of Stockholm, Stockholm, Sweden

\begin{abstract}
The crystal structure of $\mathrm{HfAl}$ is of the $\mathrm{B}_{f}(\mathrm{CrB})$ structure type. The orthorhombic unit cell, space-group $C m c m$ (No. 63), has the dimensions $a=3.25_{3} \AA, b=10.83_{1} \AA$ and $c=4.28_{2} \AA$. A comparison between $\mathrm{HfAl}$ and other $\mathrm{B}_{f}$ structures is given.
\end{abstract}

Studies on arc-melted hafnium-aluminium alloys by means of X-ray powder

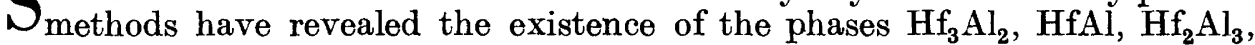
$\mathrm{HfAl}_{2}$ and $\mathrm{HfAl}_{3}$. The structure types of $\mathrm{Hf}_{3} \mathrm{Al}_{2}, \mathrm{HfAl}_{2}$ and $\mathrm{HfAl}_{3}$ were reported in a previous note ${ }^{12}, 2$. In the course of further studies on this system the crystal structure of $\mathrm{HfAl}$ has been derived.

\section{EXPERIMENTAL}

The alloy was prepared by arc-melting an equimolecular mixture of hafnium metal (98.5\% from I.C.I) and high-purity aluminium in an argon atmosphere. Crystals of HfAl were obtained by crushing the melt. They formed thin plates that could be cut down to dimensions suitable for single-crystal studies. A complete set of data was registered in a Weissenberg camera using $\mathrm{Cu} K$ radiation and rotating the crystal around an axis situated in the plane of the crystal ( $a$ axis). The intensities of the reflexions were estimated visually.

Accurate unit cell dimensions were obtained from photographs taken in a Guinier focusing camera using stirctly monochromatized $\mathrm{Cu} K a_{1}$ radiation and applying a procedure described in a previous communication from this Institute $^{3}$.

\section{DERIVATION OF THE STRUCTURE}

The single crystal data obtained showed the structure to be orthorhombic. The unit cell dimensions derived from the Guinier powder photograph were:

$$
a=3.25_{3} \AA, \quad b=10.83_{1} \AA, \quad c=4.28_{2} \AA .
$$

The observed density of 8.97 indicated that the unit cell contains 4 formula units of $\mathrm{HfAl}$, the calculated density being 9.07 . The powder pattern of HfAl is given in Table 1 .

Acta Chem. Scand. 15 (1961) No. 2 
Table 1. The Guinier powder pattern of HfAl (CuKa $a_{1}$ radiation)

\begin{tabular}{|c|c|c|c|c|}
\hline$h k l$ & $\sin ^{2} \Theta_{\mathrm{obs}}$ & $\sin ^{2} \Theta_{\text {calc }}$ & $I_{\mathrm{obs}}$ & $I_{\text {calc }}$ \\
\hline 020 & 0.02021 & 0.02023 & $\mathrm{~m}$ & 7.0 \\
\hline 021 & 0.05257 & 0.05259 & vst & 24.4 \\
\hline 110 & 0.06109 & 0.06111 & $\mathrm{mw}$ & 4.8 \\
\hline 040 & 0.08091 & 0.08091 & $\mathrm{w}$ & 3.1 \\
\hline 111 & 0.09351 & 0.09347 & vvst & 30.3 \\
\hline 130 & 0.10150 & 0.10156 & st & 16.9 \\
\hline 041 & 0.11324 & 0.11327 & st & 12.6 \\
\hline 002 & 0.12945 & 0.12944 & $\mathrm{~m}$ & 7.5 \\
\hline 131 & 0.13398 & 0.13392 & vvw & 0.6 \\
\hline 022 & 0.14970 & 0.14967 & $\mathrm{vw}$ & 1.6 \\
\hline 060 & 0.1823 & 0.18205 & & 3.0 \\
\hline 150 & & 0.18248 & $\mathrm{~m}$ & 2.4 \\
\hline 112 & 0.19056 & 0.19055 & $\mathbf{w}$ & 2.2 \\
\hline 042 & 0.21040 & 0.21035 & $\mathrm{w}$ & 2.1 \\
\hline 061 & - & 0.21441 & - & 0.1 \\
\hline 151 & 0.21486 & 0.21484 & $\mathrm{~m}$ & 7.9 \\
\hline 200 & 0.22418 & 0.22420 & $\mathrm{w}$ & 3.8 \\
\hline 132 & 0.23101 & 0.23100 & st & 12.2 \\
\hline 220 & 0.24444 & 0.24444 & $\mathrm{vw}$ & 0.9 \\
\hline 221 & 0.27673 & 0.27679 & $\mathrm{mw}$ & 5.7 \\
\hline 170 & 0.30400 & 0.30384 & $\mathrm{w}$ & 2.2 \\
\hline 240 & 0.30504 & 0.30511 & $\mathrm{vw}$ & 1.5 \\
\hline 023 & & 0.31147 & & 2.6 \\
\hline 062 & 0.3115 & 0.31149 & mst & 3.4 \\
\hline 152 & & 0.31192 & & 2.7 \\
\hline 080 & 0.32358 & 0.32365 & vvw & 0.6 \\
\hline 171 & 0.3370 & 0.33620 & $\mathrm{mw}$ & 5.7 \\
\hline 241 & & 0.33747 & $\mathrm{~m}$ & 8.3 \\
\hline 113 & 0.3530 & 0.35235 & $\mathrm{mw}$ & 7.3 \\
\hline 202 & & 0.35364 & $\mathrm{mw}$ & 5.5 \\
\hline 081 & 0.35606 & 0.35601 & $\mathbf{w}$ & 4.1 \\
\hline 043 & 0.37209 & 0.37215 & w & 4.1 \\
\hline 133 & - & 0.39280 & - & 0.2 \\
\hline 260 & 0.40626 & 0.40625 & $\mathrm{w}$ & 3.4 \\
\hline 172$\}$ & 0.4335 & 0.43328 & $\mathrm{~m}$ & 4.5 \\
\hline 242$\}$ & 045322 & 0.43455 & & 3.1 \\
\hline 082 & $\begin{array}{l}0.45322 \\
0.46557\end{array}$ & 0.45309 & $\mathrm{vw}$ & 1.4 \\
\hline 190 & 0.46557 & 0.46567 & $\mathrm{mw}$ & 4.5 \\
\hline $\left.\begin{array}{l}063 \\
153\end{array}\right\}$ & 0.4735 & $0.47329\}$ & $\mathrm{mw}$ & 0.1 \\
\hline $153 \gamma$ & & 0.47372 & & 7.0 \\
\hline
\end{tabular}

Reflexions $h k l$ were observed only for $h+k=2 n, 0 k l$ for $k=2 n, h 0 l$ for $h=2 n$ and $l=2 n$ and $h k 0$ for $h+k=2 n$. The probable space-groups thus are $C m c m$ (No. 63), Cmc2 $2_{1}$ (No. 36) and $A m a 2$ (No. 40). The symmetry, the unit-cell dimensions and the appearance of the Patterson projection along [100] suggested that the phase is isomorphous with CrB. Both the hafnium and aluminium atoms are thus in the point positions $4(c)$ of the space-group Cmcm:

$$
\pm\left(0, y, \frac{1}{4}\right) ; \quad \pm\left(\frac{1}{2}, \frac{1}{2}+y, \frac{1}{4}\right)
$$

Approximate values of the $y$ parameters were obtained from the Patterson projection and the signs of the $F(0 k l)$ could be calculated. The projection of 


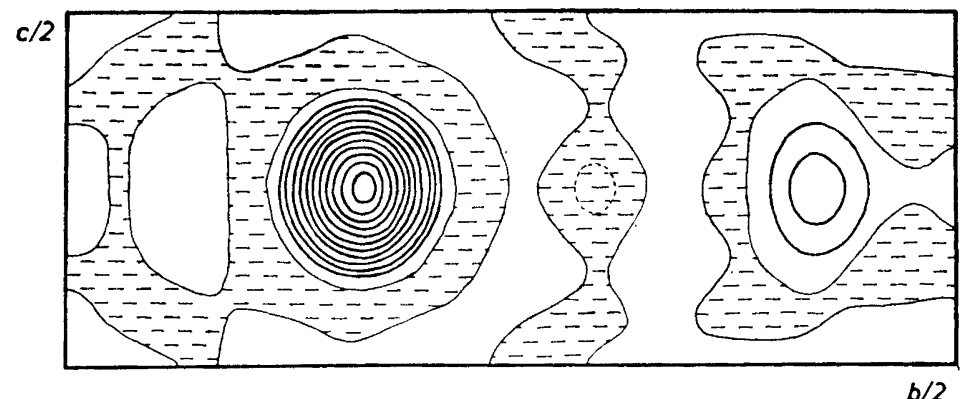

Fig. 1. a). Projection along [100] of the electron density of HfAl.

the electron density along [100] thus calculated (cf. Fig. la) gave the following parameter values:

$$
y_{\mathrm{Hf}}=0.167 \quad y_{\mathrm{Al}}=0.42_{5}
$$

The difference synthesis $\varrho\left(F(0 k l)_{\text {obs }}-F(0 k l)_{\text {Hf }}\right)$ gave the same value for the $y_{\mathrm{A} 1}$ parameter (cf. Fig. 1b). However, the accuracy of the aluminium position is rather low due to the relatively low scattering power of this atom. The index of agreement

$$
\Sigma|| F(0 k l)_{\text {obs }}|-| F(0 k l)_{\text {calc }}|| / \Sigma\left|F(0 k l)_{\text {obs }}\right|
$$

corresponding to this structure is 0.11 . Table 1 gives a comparsion between calculated and observed powder intensity data. The interatomic distances are given in Table 2.

\section{DISCUSSION}

Following Frank and Kasper ${ }^{4}$, the structure of $\mathrm{HfAl}$ can be described as a $3^{3} \cdot 4^{2}$ tessilation in the $z=\frac{1}{4}$-plane. This tessilation repated by the $2_{1}$ axes parallel to [001] is demonstrated in Fig. 2. It is interesting to note that the zig-zag aluminium chains thus formed (A-B in Fig. 2) have quite normal

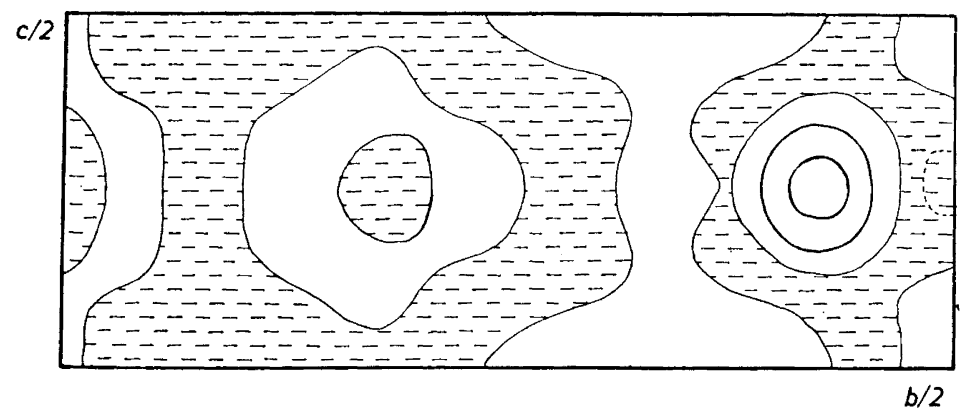

Fig. 1. b). The difference synthesis $\varrho\left(F(0 k l)_{\mathrm{obs}}-F^{\prime}(0 k l)_{\mathrm{Hf}}\right)$. Shadowed areas indicate negative values. 
Table 2. Interatomic distances in HfAl.

Hf

$\begin{array}{lll}4 \mathrm{Hf} & 3.26 \\ 2 \mathrm{Hf} & 3.25 \\ 4 \mathrm{Al} & 2.86 \\ 2 \mathrm{Al} & 3.07 \\ 1 \mathrm{Al} & 2.82\end{array}$

Al

distances of about $2.69 \AA$. The corresponding boron-boron distances in CrB determined by Kiessling are extremely short and are probably due to boronboron bonds of a covalent type ${ }^{5,6}$.

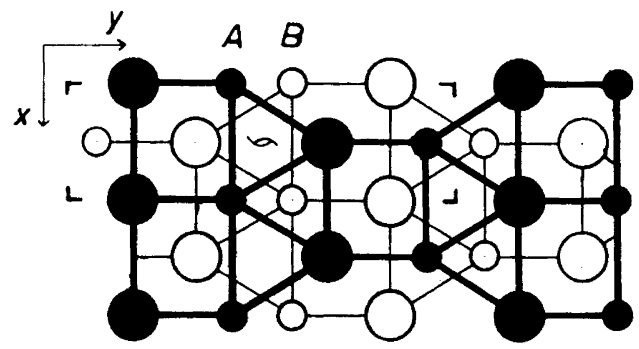

Fig. 2. The $3^{3} \cdot 4^{2}$ tessilation of HfAl. Large (Hf) and small (Al) black circles represent atoms at $z=\frac{1}{6}$ and open ones atoms at $z=3$. The unit cell is indicated by $L$.

The isomorphism between $\mathrm{HfAl}$ and $\mathrm{ThAl}$ (described by Braun ${ }^{7}$ on a different system of axes) is also of considerable interest since the aluminiumaluminium distances along the zig-zag chains of the latter phase are reported to be as short as $2.46 \AA$. It might be that this is a matter of the relative size of the atoms, the ratios $r_{\mathrm{Th}} / r_{\mathrm{Al}}$ and $r_{\mathrm{Cr}_{\mathrm{r}}} / r_{\mathrm{B}}$ being approximately the same and substantially higher than $r_{\mathrm{Hf}} / r_{\mathrm{Al}}$. However, the analogous crystal structure of ThCo does not support this assumption ${ }^{8}$ since the cobalt-cobalt distances are $2.77 \AA$ in spite of the atomic radius of cobalt being less than that of aluminium.

The atomic distances within the chains of several other phases of $B_{f}$ structure, uncluding $\mathrm{CaSi}^{9}, \mathrm{CaGe}^{10}, \mathrm{CaSn}^{10}$ and $\mathrm{YSi}^{11}$, are throughout of the long "normal" type.

The author wishes to thank Dr. Arne Magnéli for his never failing support and many valuable discussions.

\section{REFERENCES}

1. Edshammar, L.-E. and Andersson, S. Acta Chem. Scand. 14 (1960) 223.

2. Edshammar, L.-E. Acta Chem. Scand. 14 (1960) 1220.

3. Westman, S. and Magnéli, A. Acta Chem. Scand. 11 (1957) 1587.

4. Frank, F. C. and Kasper, J. S. Acta Cryst. 12 (1959) 483.

5. Kiessling, R. Acta Chem. Scand. 3 (1949) 595.

6. Kiessling, R. Acta Chem. Scand. 4 (1950) 209.

7. Braun, P. B. and van Vucht, J. H. N. Acta Cryst. 8 (1955) 246.

8. Florio, J. V., Baenziger, N. C. and Rundle, R. E. Acta Cryst. 9 (1956) 367.

9. Hellner, E. Z anorg. Chem. 261 (1950) 226.

10. Eckerlin, P., Mayer, H. I. and Wölfel, E. Z. anorg. Chem. 281 (1955) 322.

11. Parthé, E. Acta Cryst. 12 (1959) 559.

Received October 5, 1960. 